\title{
Modelo experimental em ratos para o desenvolvimento de pseudoartrose
}

\section{Experimental model in rats for the development of pseudoarthrosis}

Manoel luiz Ferreira ${ }^{1}$; Paulo Cesar Silva 2 ; Lara de Paula Miranda Pereira3; Renata Schueler Franco3; Natalia Bernades Mello3; Alessandra Cintra Amaral ${ }^{3}$; Alberto Schanaider, TCBC-RJ4

\section{RE S U M O}

\begin{abstract}
Objetivo: Descreve-se a técnica de um novo um modelo de pseudoartrose em Rattus norvegicus albinus livre de espécies patogênicas (SPF). Métodos: Os animais foram aleatoriamente distribuídos em dois Grupos: Grupo 1 - Controle $(n=6)$, Grupo 2 - Experimental $(\mathrm{n}=6)$. No grupo Controle realizou-se um acesso ao fêmur, seguido da síntese por planos do músculo e da pele. O grupo Experimental foi submetido à osteotomia do fêmur aduzida da confecção de um retalho pediculado de fáscia lata para interposição entre os segmentos resultantes da fratura induzida cirurgicamente. Prosseguiu-se com o alinhamento e aproximação dos segmentos ósseos, mediante uso de fios de náilon introduzidos em orifícios efetuados na extremidade proximal e distal. Resultados: Estudos radiológico e anatomopatológico evidenciaram a ausência de consolidação óssea com persistência de tecido fibro-osteóide decorridos 120 dias de evolução pós-operatória. Conclusão: O modelo experimental é adequado para a formação de pseudoartrose em ratos.
\end{abstract}

Descritores: Ratos. Pseudoartrose. Osteotomia. Modelos animais.

\section{INTRODUÇÃO}

A estrutura óssea é a responsável pela sustentação e a forma do corpo. O osso tem uma marcante combinação de propriedades físicas dentre as quais a resistência à tensão e à compressão, alguma elasticidade e estrutura porosa e com peso da massa sólida relativamente leve. Trata-se de um tecido em constante renovação e reconstituição e que sobressai pela sua capacidade autoreparadora. Pode alterar sua propriedade de consolidação e a geometria trabecular em resposta a estímulos mecânicos que incidam sobre ele?.

Fratura é uma solução de continuidade do tecido ósseo causado, geralmente, por traumas ou ainda doenças metabólicas, endócrinas, tumorais e infecciosas. A ação de um agente vulnerante externo, principal causa, resulta no rompimento de vasos que compõem a rede da medula óssea, bem como no dano aos tecidos circunvizinhos. Tais condições facilitam a instalação de processos necróticos ${ }^{2-5}$ e que, por sua vez, interferem com a evolução fisiológica da cicatrização $0^{3,6}$ e predispõem ao aparecimento de deformidades ou a ausência da consolidação óssea.

Pseudoartrose é o termo usado para designar a não consolidação de uma fratura, quando o processo de reparação óssea, por algum motivo deixou de atuar. A fal- ta da união das superfícies ósseas fraturadas decorre da presença de um tecido fibroso ou fibro-cartilaginoso entre as extremidades? .

Contribuem para a persistência deste problema a instabilidade do foco da fratura ou causas biológicas como a falta de aporte sanguíneo adequado.

Considerando os elevados custos sócioeconômicos decorrentes das sequelas e da incapacidade laboral e a inexistência de consenso quanto ao meIhor tratamento da pseudoartrose, os autores objetivaram criar um modelo experimental de baixo custo capaz de refinar estudos terapêuticos para esta afecção.

\section{MÉTODOS}

O trabalho foi aprovado pelo Comitê de Ética para o Uso de Animais de Laboratório em Pesquisa do Departamento de Cirurgia da Faculdade de Medicina da UFRJ.

Para o desenvolvimento do presente experimento foram utilizados 12 animais Rattus norvegicus albinus, linhagem Wistar SPF, adultos jovens, de ambos os sexos, com peso médio de $300 \mathrm{~g}$ na data da cirurgia, distribuídos aleatoriamente em dois grupos numericamente iguais: Grupo $1(n=6)$, Controle e grupo $2(n=6)$, Experimental.

Trabalho realizado no Centro de Cirurgia Experimental do Programa de Pós-Graduação em Cirurgia do Departamento de Cirurgia da Faculdade de Medicina da UFRJ - Rio de Janeiro - BR-BR.

1. Aluno do Doutorado do Programa de Pós Graduação do Departamento de Cirurgia da Faculdade de Medicina - UFRJ - Rio de Janeiro - RJBR. 2. Professor Adjunto do Centro de Cirurgia Experimental - do Departamento de Cirurgia da Faculdade de Medicina - UFRJ - Rio de Janeiro - RJ-BR. 3. Alunos do Curso de Graduação- Faculdade de Medicina -UFRJ_Rio de Janeiro - RJ-BR. 4. Coordenador do Programa de PósGraduação em Ciências Cirúrgicas do Departamento de Cirurgia da Faculdade de Medicina - UFRJ- Rio de Janeiro-RJ-BR. 
Os animais foram mantidos em temperatura controlada, com uso de ração industrializada padrão e água ad libitum.

Todos os animais foram obtidos no Biotério do Centro de Cirurgia Experimental do Departamento de Cirurgia, da Faculdade de Medicina da UFRJ.

A medicação anestésica foi administrada por via intraperitonial, com Ketamina 10\% (10mg/ $/ \mathrm{kg})$ e Xilazina $2 \%(10 \mathrm{mg} / 100 \mathrm{~g})$. Após os cuidados de antissepsia e assepsia realizaram-se as operações.

No grupo 1 efetuou-se uma incisão cutânea de 5 $\mathrm{cm}$, longitudinal, na região lateral externa da coxa esquerda, com divulsão dos músculos vasto lateral e bíceps femoral, seguida por rigorosa hemostasia. Após identificação do fêmur, procedeu-se a rafia dos planos musculares e da pele, respectivamente com fio poliglicólico 4-0, com agulha cilíndrica e fio de náilon 4-0, com agulha cortante.

No grupo 2, os procedimentos de acesso ao fêmur esquerdo foram similares a do grupo 1. Realizou-se uma osteotomia interessando a diáfise do fêmur, com uso de serra circular elétrica em baixa rotação, irrigada com solução salina 0,9\% para evitar o aquecimento da serra e do osso (Figura 1). Em cada segmento ósseo a uma distância

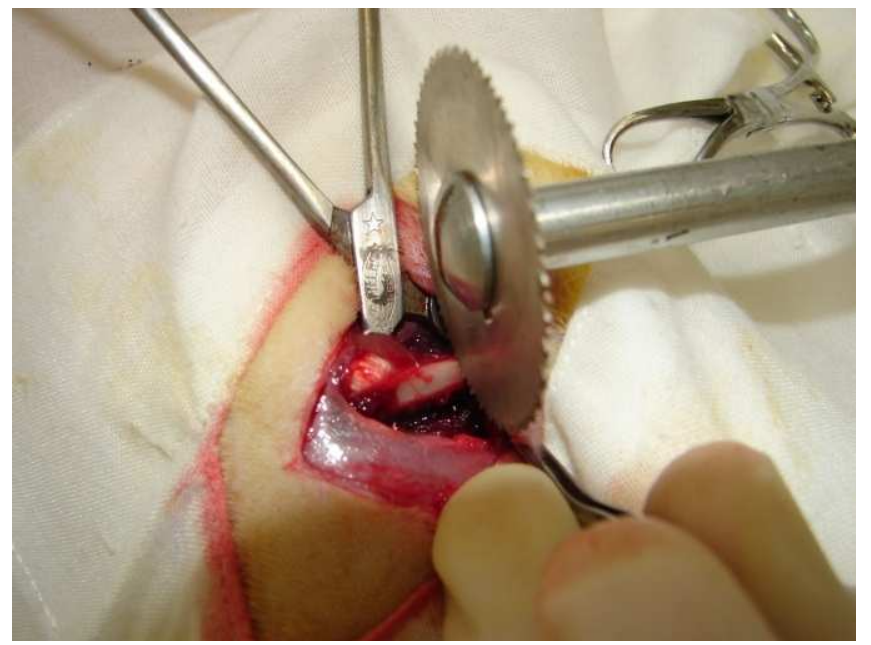

Figura 1- Osteotomia do fêmur com serra circular.

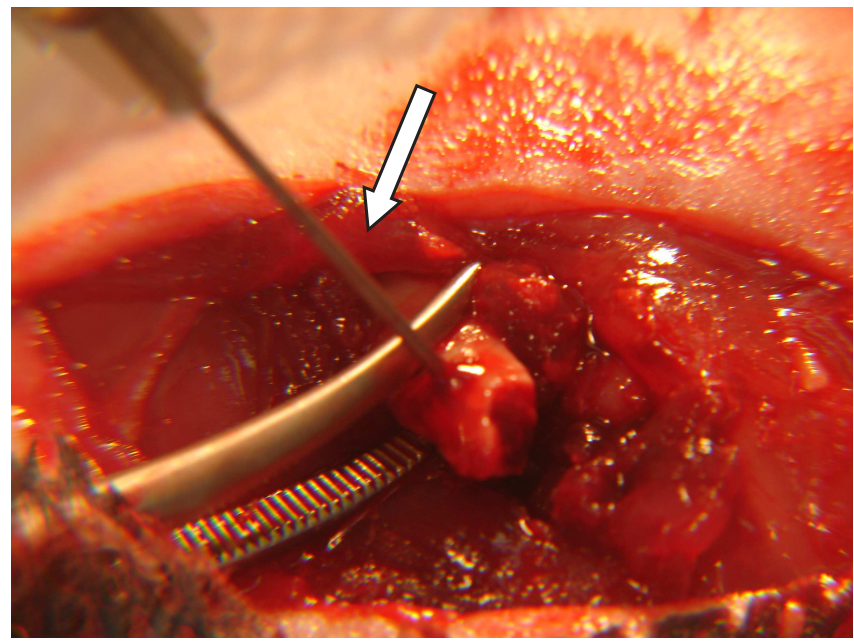

Figura 2 - $\quad$ Perfuração perpendicular com agulha hipodérmica (seta). de aproximadamente $3 \mathrm{~mm}$ da borda da osteotomia procedeu-se uma perfuração transfixante perpendicular com aguIha hipodérmicas $27 \times 8$, com movimentos circulares(Figura 2), por onde foram introduzidos fios monofilamentares de náilon 3-0(Figura 3). Confeccionou-se, então, um retalho pediculado da fáscia lata para interposição nos segmentos da fratura, com sutura da sua extremidade distal ao músculo semimembranáceo, seguido da rafia óssea em formato de $U$, aproximando o segmento proximal e o distal(Figura 4). Por fim, fez-se a síntese dos planos musculares e da pele, de modo semelhante descrita para o grupo 1.

A analgesia utilizada no pós operatório se fez com dipirona (20 gotas em $500 \mathrm{ml}$ de água) colocada no bebedouro, cujo conteúdo era trocado diariamente, durante sete dias.

Foi avaliado, ainda no pós-operatório, até aos 120 dias, o grau de claudicação de acordo com uma escala crescente de gravidade ${ }^{8}$ (Tabela 1 ), além da mobilidade e posição do membro posterior esquerdo.

Com 30 e 120 dias de pós-operatório, os membros posteriores esquerdos de todos os animais foram radiografados com o aparelho de Raio X de 60Kv, 10mA com exposição de dois segundos.

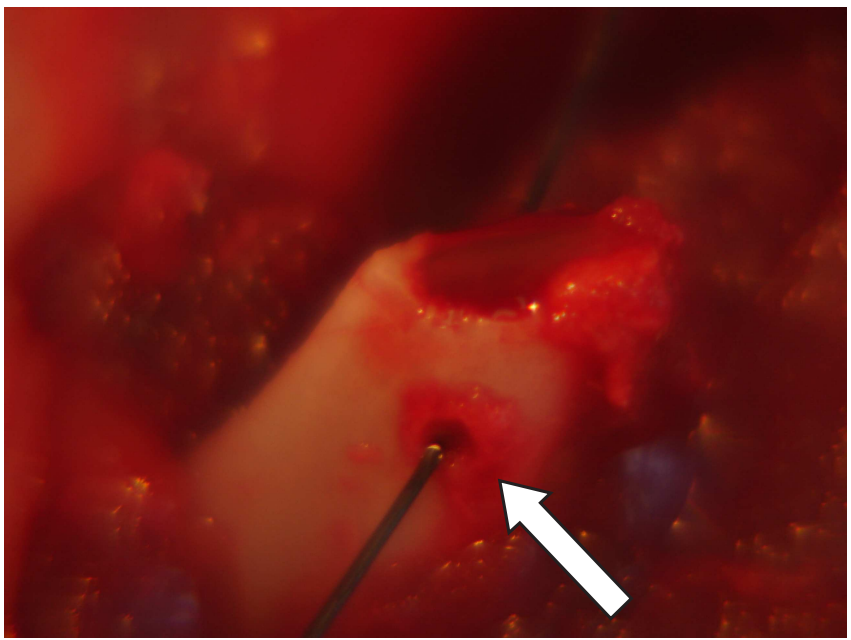

Figura 3 - Fio de náilon 3-0 transfixado a 3mm da extremidade seccionada do osso (seta).

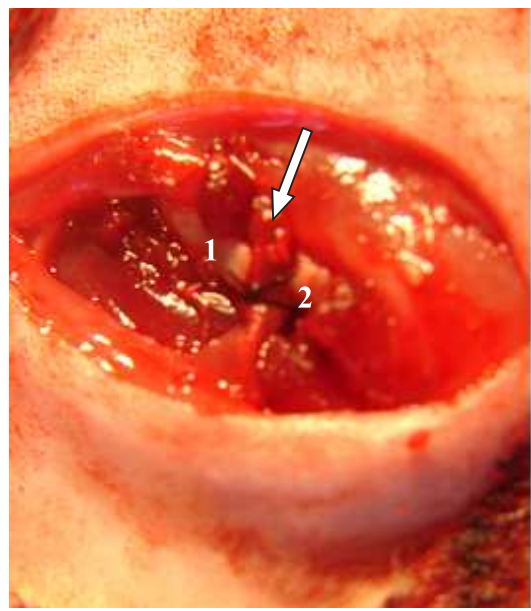

Figura 4 - Fáscia lata (seta) entre os segmentos ósseos alinhados por ponto em U com fio de náilon 3-0 (1 e 2). 
Tabela 1 - Classificação da deambulação.

\begin{tabular}{ll}
\hline Grau & Critério \\
\hline 1 & Claudicação ausente; apoio completo do membro com o animal em estação ou durante atividade física. \\
2 & Claudicação discreta após exercício ou decúbito prolongado. \\
3 & Claudicação esporádica ao caminhar ou correr, com alívio do peso sobre o membro operado, inclusive em estação. \\
4 & Claudicação constante ao caminhar e não apoio do membro ao correr; apoio incompleto em posição ortostática. \\
5 & Apoio incompleto ou ausente durante atividades físicas ou em estação.
\end{tabular}

Ao final dos 120 dias procedeu-se a eutanásia dos animais do grupo 2 com aplicação de $4 \mathrm{ml}$ de tiopentato de sódio 2,5\%, por via intraperitonial e foram coletadas, em bloco, amostras do fêmur esquerdo e de tecidos circunvizinhos à região da pseudoartrose, para realização de exame anatomopatológico. As preparações histológicas foram coradas com Hematoxilina-Esosina e analisadas, sob microscopia óptica, em aumento de 250 vezes.

\section{RESULTADOS}

Todos os animais do grupo 1 operados se recuperaram sem nenhuma sequela.

A avaliação dos animais do grupo 2 e de seu grau de claudicação no pós-operatório até os 120 dias, de acordo com os critérios contidos na tabela 1 evidenciou apoio incompleto, claudicação grau 5 do membro posterior esquerdo com perda da função, posição anormal e mobilidade insólita entre os segmentos da fratura. Após os períodos de 30 e 120 dias de pós-operatório, o estudo radiológico não revelou consolidação óssea, ou seja, calcificação entre os segmentos da fratura (Figura 5). Os exames anatomopatológicos evidenciaram presença de tecido de aspecto fibro-osteoide (Figura 6).

\section{DISCUSSÃO}

Estima-se nos Estados Unidos da América, que ocorram 5,6 milhões de fraturas por ano, sendo que 5 a

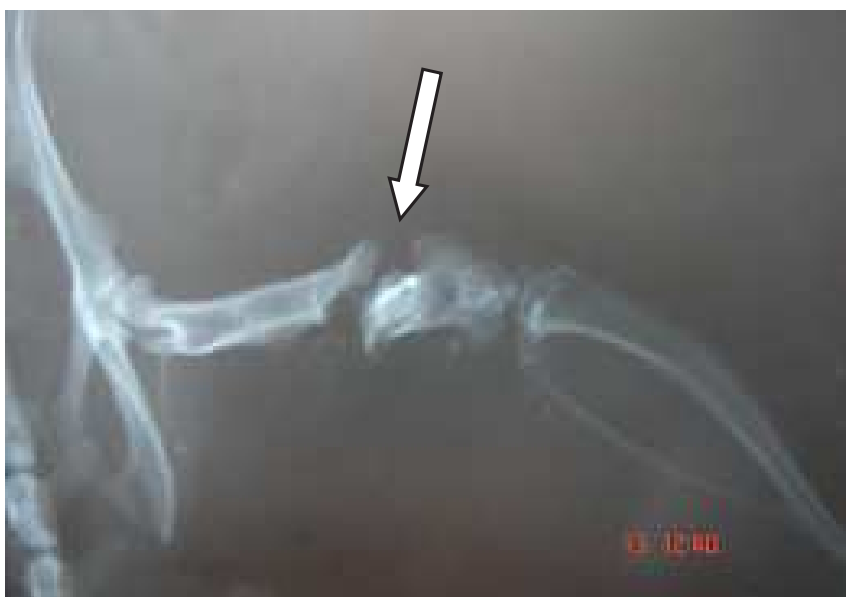

Figura 5 - $\quad$ Radiografia do membro posterior esquerdo após 120 dias de pós-operatório evidenciando a ausência de união óssea (seta).
10\% evoluem para um atraso da consolidação óssea ou formação da pseudoartrose ${ }^{9}$.

As causas de não consolidação óssea estão relacionadas a inúmeros fatores dentre os quais sobressaem: o alcoolismo, o tabagismo, a doença periférica microangiopática, alterações de comportamento de ordem psicológica, os distúrbios metabólicos, as hipovitaminoses, a imobilização prolongada e inadequada, a doença metastática, o hiperparatireoidismo, a distração excessiva da fratura na fixação externa, a fratura exposta, a infecção e a interposição de tecidos moles na fratura ${ }^{10,11}$.

De acordo com o tipo de pseudoartrose e o perfil de atividade física do paciente, vários métodos têm sido utilizados no tratamento, tais como: a descorticação ou escamação osteoperiostal, o autoenxerto esponjoso, a adição de BMP (proteína morfogenética óssea), o concentrado de células-tronco da medula óssea, fatores de crescimento plaquetário, a distração do calo ósseo com fixadores externos, o enxerto ósseo vascularizado nas perdas ósseas, os materiais de estabilização interna (placa de compressão, pino ou haste intramedular fresada e bloqueada), os estabilizadores externos (fixadores externos ou órteses), além do ultrassom, ondas de choque e campos eletromagnéticos ${ }^{12-14}$. Esta plêiade de opções apenas reflete a ausência de um consenso sobre a melhor conduta nas pseudoartroses e que, por sua vez, causa uma condição grave, incapacitante, deformante e com grande ônus social e econômico para as famílias e os serviços públicos de saúde.

Assim, a elaboração adequada de pseudoartrose em animais permitirá sua aplicação em no-

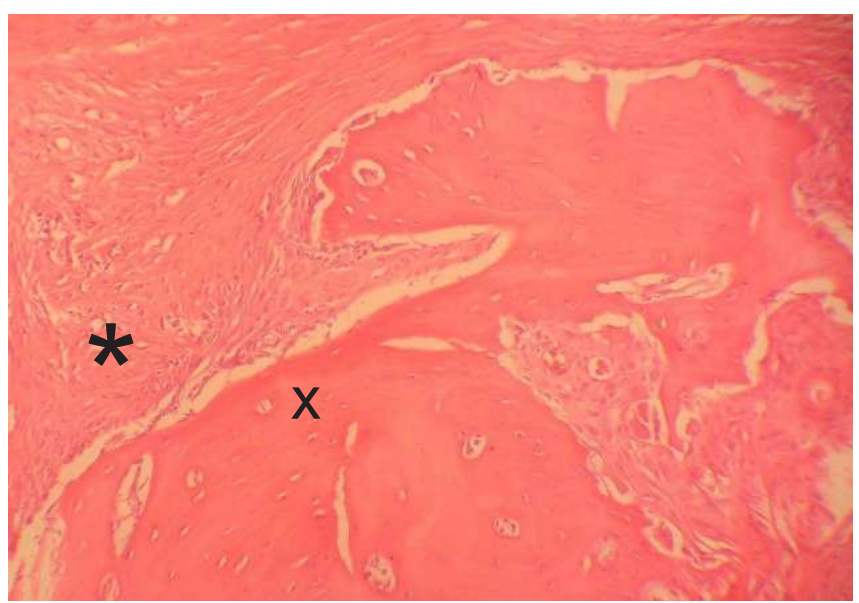

Figura 6 - Tecido osteofibroso $\left(^{*}\right)$.

tecido ósseo(x). HE $\times 40$ 
vas terapêuticas para obtenção de uma conduta mais eficaz e objetiva. Todavia, há uma grande dificuldade para se reproduzir a não união óssea, porquanto os modelos experimentais que produzem fratura óssea sempre se acompanham de lesões relevantes em tecidos circunvizinhos ${ }^{15,16}$.

Diversas espécies animais são utilizadas para criar uma pseudoartrose ${ }^{13,17-21}$, mas enfocam, precipuamente, a relevância da vascularização para a gênese desta doença, ou a extensão do segmento ósseo comprometido.

A escolha de ratos da linhagem Wistar SPF se deu por serem animais criados em biotério próprio, de pequeno porte, de fácil manutenção e por apresentarem aspectos anatômicos, a exemplo da parte óssea, recoberta por grande massa muscular, comparáveis aos da espécie humana.

Resultados variáveis (86 a 95\%) com êxito na obtenção de modelos de pseudoartrose em cães são descritos após três a sete meses do ato operatório ${ }^{19}$. Na pesquisa atual,foram observados $100 \%$ de resultados positivos na produção da lesão, com quatro meses de pós-operatório. Assim, apesar do modelo se assemelhar, quanto ao prazo, aos resultados obtidos por outros autores em outra espécie, há como vantagens a utilização de um animal com menor custo de manutenção e logística da operação.

Os osteoblastos exigem estabilidade perfeita, para que os capilares promovam a revascularização, possam cruzar as linhas de fratura e facilitar a transformação de células pluripotentes em osteoblastos, possibilitando a remodelação haversiana primária sem que o calo periosteal ocorra ${ }^{14,22,23}$. No modelo utilizado a falta de estabilidade entre os segmentos da fratura foi fundamental para que não houvesse calcificação do tecido entre os segmentos osteotomizados, e consequentemente a formação de pseudoartrose. Deste modo, buscou-se manter o movimento no foco da fratura, mas com bom suprimento sanguíneo. Enfatiza-se que, mesmo na presença de pseudoartrose, se a estabilidade for alcançada naturalmente, ou for produzida por fixação externa ou interna, a calcificação da cartilagem poderá ocorrer, o que, subsequentemente, possibilita a substituição da cartilagem por osso, como no processo de ossificação endocondral6,12,16. Há de se ressaltar que a simples secção óssea com uma redução da fratura e fixação frágil, a exemplo de fios monofilamentares, não é suficiente para impedir a formação do calo ósseo. Este poderá se formar em uma posição viciosa, o que significa que as extremidades podem se calcificar desalinhadas, ou seja, fora do eixo longitudinal normal. A compreensão desta dinâmica foi crucial para o desenvolvimento do modelo, porquanto, para garantir a presença da pseudoartrose, não bastava à presença de uma fratura com uma fixação pouco estável. Faz-se necessário a interposição do retalho pediculado da fáscia lata, fundamental para que a cicatrização óssea não ocorresse, ou seja, que não houvesse a recuperação espontânea. Não foram encontradas descrições similares na literatura sobre o assunto. A ráfia em formato de $U$ facilitou a interposição e a manutenção da fáscia lata entre os segmentos da fratura, induzida cirurgicamente. A fixação da extremidade distal da fáscia lata ao músculo semimembranáceo evitou o seu deslocamento, ao longo da evolução pós-operatória.

A presença de tecido fibro-osteóide, ao exame histopatológico caracterizou a existência pseudoartrose, no pós-operatório.

O resultado do exame radiológico evidenciou a ausência de união dos seguimentos ósseos, por imagem, compatível a pseudoartrose hipertrófica.

Destarte, o modelo inédito apresentado adequouse a produção da pseudoartrose em ratos e possibilitará o seu uso para o estudo e desenvolvimento de procedimentos terapêuticos inclusive com o aproveitamento dos conceitos já acumulados da regeneração de tecidos, provenientes de células pluripotenciais.

\title{
A B S S T R A C T
}

\begin{abstract}
Objective: We sought to describe a new model of pseudoarthrosis in rats free of pathogenic species (Rattus norvegicus albinus SPF). Methods:The animals were randomly distributed into two groups were used: Group 1 - Control $(n=6)$; Group 2 - Experimental $(n=6)$. In the Control group an access to the femur followed by the synthesis of the muscular and skin layers was done. The Experimental group was submitted to osteotomy of the femur and a pedicle flap of the fascia lata was interposed between the segments resulting from the surgically induced fracture. The procedure was carried on with both alignment and approximation of the fractured bone through the use of mononylon thread introduced into holes created in the proximal and distal. Results: Radiological and anatomopathological studies showed the absence of bone consolidation with persistence of fibro-osteoid tissue up to 120 days of follow-up. Conclusion The experimental model is suitable for the development of a pseudoarthrosis in rats.
\end{abstract}

Key words: Rats. Pseudarthrosis. Osteotomy. Models, animal.

\section{REFERÊNCIAS}

1. Kaplan FS, Hayes WC, Keaveny TM et al. Form and function of bone. In: Simon SP, Wilson J, editors. Orthopedic basic science. Chicago: American Academy of Orthopaedics Surgeons; 1994. p.127-84.

2. Carano RAD, Filvaroff EH. Angiogenesis and bone repair. Drug Discov Today. 2003; 8(21):980-9.
3. de Muinck ED, Simons M. Re-evaluating therapeutic neovascularization. J Mol Cell Cardiol. 2004; 36(1):25-32.

4. Doblaré M, García JM. On the modelling bone tissue fracture and healing of the bone tissue. Acta Cient Venez. 2003; 54(1):58-75.

5. Karladani $A H$, Granhed $H$, Kärrholm J, Styf J. The influence of fracture etiology and type on fracture healing: a review of 104 consecutive tibial shaft fractures. Arch Orthop Trauma Surg. 2001; 121(6):325-8. 
6. Bostrom MP, Saleh KJ, Einhorn TA. Osteoinductive growth factors in preclinical fracture and long bone defects models. Orthop Clin North Am.1999; 30(4):647-58.

7. Hietaniemi K, Paavolainen P, Penttienen R. Connective tissue parameters in experimental nonunion. J Orthop Trauma. 1996; 10(2):114-8.

8. Muzzi LAP, Rezende CMF, Muzzi RAL, Borges NF. Ruptura do ligamento cruzado cranial em cães: fisipatologia e diagnóstico. Clin Vet. 2003; 46(1):32-42.

9. Einhorn TA. Enhancement of fracture-healing. J Bone Joint Surg Am. 1995; 77(6):940-56.

10. Selgaman KA, Clark GL. Un-united fractures of the distal radius: a report of 12 cases. J Hand Surg. 1998; 23(5):914-9.

11. Smith VA, Wright TW. Nonunion of the distal radius. J Hand Surg Br. 1999; 24(5):601-3.

12. Schenk RK. Histology of fracture repair and nonunion. Bull Swiss Assoc Study Intern Fixation.1978:32-7.

13. Kokubu T, Hak DJ, Hazelwood SJ, Reddi AH. Development of an atrophic nonunion model and comparison to a closed healing fracture in rat femur. J Orthop Res. 2003; 21(3):503-10.

14. Russel G, Tucci M, Conflitti J, Graves M, Wingerter S, Woodall J Jr, Rabag A, Benghuzzi $H$. Characterization of a femoral segmental nonunion model in laboratory rats: report of a novel surgical technique. J Invest Surg. 2007; 20(4): 249-55.

15. Wong HL, Wahl SM. Inflammation and repair. In: Sporn MB, Boberts $A B$. Peptide growth factors and their receptors. New York: Springer - Verlag; 1990. p. 509-48.

16. Grundnes $\mathrm{O}$, Reikeras $\mathrm{O}$. The importance of the hematoma for fracture healingin rats. Acta Orthop Scand. 1993; 64(3):340-2.

17. Duarte LR. The stimulation of bone grow by ultrasound. Arch Orthop Trauma Surg. 1983; 101(3):153-9.
18. Chakkalakal DA, Strates BS, Mashoof AA, Garvin KL, Novak JR, Fritz ED, Mollner TJ, McGuire MH. Repair of segmental bone defects in the rat: an experimental mode human fracture healing. Bone. 1999; 25(3):321-32.

19. Volpon JB. Nonunion using a canine model. Arch Orthop Trauma Surg. 1994; 113(6):312-17.

20. Forriol F. The effect of shockwaves on mature and healing cortical bone. Int Orthop. 1994; 18(5):325-9.

21. Seemann O, Rassweiler J, Chvapil M, Alken P, Drach GW. Effect of low dose shock wave energy on fracture healing: an experimental study. J Endourol. 1992; 6(2):219-23.

22. Khan $Y$, Laurencin CT. Fracture repair with ultrasound: clinical and cell-based evaluation. J Bone Joint Surg Am. 2008; 90 Suppl 1:138-44.

23. Schleberger $R$, Senge $T$. Non invasive treatment of long bone pseudarthrosis by shock waves. Arch Orthop Trauma Surg. 1992; 111(4): 224-7.

Recebido em 11/12/2008

Aceito para publicação em 09/02/2009

Conflito de interesse: nenhum

Fonte de financiamento: nenhuma

\section{Como citar este artigo:}

Ferreira ML, Silva PC, Pereira LPM, Franco RS, Mello NB, Amaral AC, Schanaider A. Modelo experimental em ratos para o desenvolvimento de pseudoartrose. Rev Col Bras Cir. [periódico na Internet] 2009; 36(6). Disponível em URL: http://www.scielo.br/rcbc

\section{Endereço para correspondência:}

Alberto Schanaider

E-mail: alberto-sch@ig.com.br 